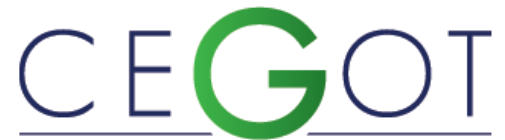

Centro de Estudos de Geografia e Ordenamento do Território
Geografia e Ordenamento do Território, Revista Eletrónica Centro de Estudos de Geografia e Ordenamento do Território http://cegot.org

RIBEIRO, JOSÉ

IGCE/Universidade Estadual Paulista "Júlio de Mesquita Filho" 13506-900. Avenida 24 A, 1515 - Jd. Bela Vista. Rio Claro - SP - Brasil joserenatorbr@gmail.com

\section{Chamusca, Pedro}

Departamento de Ciências Sociais, Políticas e do Território da Universidade de Aveiro / CEGOT

Universidade de Aveiro, Campus Universitário de Santiago, 3810-193

Aveiro,Portugal

pedrochamusca@ua.pt

\title{
Governança territorial, Atores e Desenvolvimento: um estudo sobre a organização territorial do cluster do calçado português
}

Territorial governance, stakeholders and development: a study on the territorial organization of the Portuguese footwear cluster

Referência: Ribeiro, José; Chamusca, Pedro (2020). Governança territorial, Atores e Desenvolvimento: um estudo sobre a organização territorial do cluster do calçado português. Revista de Geografia e Ordenamento do Território (GOT), n. 19 (junho). Centro de Estudos de Geografia e Ordenamento do Território, p. 186-217, dx.doi.org/10.17127/got/2020.19.008

\section{RESUMO}

Reconhecida como a "a indústria mais sexy da Europa", a indústria calçadista portuguesa se consolida como símbolo nacional, superando os problemas que outrora vivenciou. Nesse processo de consolidação, a atuação da associação empresarial foi fundamental no estabelecimento dos vínculos de cooperação e do movimento de coordenação dos atores, aspectos relevantes para a obtenção dos resultados positivos. Consideramos a coordenação exercida pela associação um dos elementos centrais das estruturas de governança territorial, tema que tem sido foco de importantes debates no campo do planejamento urbano-regional e da gestão do território. Dito isso, o presente artigo objetivou analisar a importância da governança territorial em aglomerados produtivos, como o cluster do calçado português. Para tanto, a metodologia foi constituída de revisão bibliográfica e da análise de documentos oficiais, além de estudos recentes sobre a dinâmica do cluster. Os resultados alcançados demonstraram a importância da governança no desempenho dos clusters, além de oferecer, com base no estudo de caso, um exemplo para a discussão sobre a dinâmica em aglomerados produtivos e a relevância dos novos fatores de produção (conhecimento, inovação, articulação entre atores, apoio institucional).

Palavras-chave: Governança; Atores; Desenvolvimento; Cluster.

\section{ABSTRACT}

Recognized as "the sexy industry in Europe", the Portuguese footwear industry consolidates itself as a national symbol, overcoming the problems that affected it during decades. In this consolidation process, the role of the business association was fundamental in establishing cooperation links and the coordination between stakeholders, aspects that are relevant to 
the positive results. This coordination is a central element of the territorial governance structure, a topic that has been the focus of important debates in the field of urban-regional planning and spatial management. That said, this article aims to analyze the importance of territorial governance in agglomerated products, such as the Portuguese footwear cluster. For that, a methodology combining the theoretical review, official documents analysis and interviews was used. The results demonstrated the importance of governance in the performance of the cluste, highlighting the relevance of the new production factors (knowledge, innovation, articulation between institutional support)

Keywords: Governance; Actors; Development; Cluster.

\section{Introdução}

As mudanças ocorridas no interior do Estado (reformas político-administrativas), aliadas a reorganização da produção, atingiram profundamente o cerne das políticas de planejamento regional e de gestão do território, os quais tinham, no poder central, o principal formulador. Tratam-se de mudanças na elaboração das políticas de planejamento e gestão territorial, que evidenciam uma segunda dimensão do processo de globalização, caracterizado pelo surgimento de novos modelos ou padrões de ação coletiva, inserção das análises multiescalares e no aparecimento de formas de parceria, cooperação institucional e de planejamento estratégico, englobando o envolvimento de novos atores.

Esses resultados podem ser observados na existência de iniciativas específicas de desenvolvimento territorial, caracterizadas por ações, estratégias e políticas para a (re)construção da base produtiva local/regional, podendo, ou não, provocar impactos no território. Nesse sentido, a existência de dispositivos institucionais de cooperação e de coordenação das ações é um critério essencial para o bom funcionamento. Esses dispositivos institucionais têm recebido a denominação de estruturas de governança territorial e podem ser exemplificados em diferentes manifestações nos processos de gestão urbana, planos estratégicos, orçamentos participativos, planos de ordenamento do território, comitês de bacias hidrográficas, clusters, entre outros.

Ao considerar a governança territorial como um dos debates atuais nos estudos sobre planejamento, gestão e desenvolvimento do território, o objetivo do artigo é o de analisar a sua importância no cluster do calçado português, considerado uma das principais indústrias do país. No estudo proposto, é essencial considerarmos a política destinada aos clusters portugueses, que tem, como principal documento orientador, o Regulamento de Reconhecimento dos Clusters de Competitividade. 
O artigo está organizado em sete seções, iniciando com essa introdução. Na segunda seção, apresentamos a problemática da governança como novo modo de cooperação e de coordenação dos territórios para o desenvolvimento. Na terceira seção, apresentamos a definição de cluster e as políticas de apoio as aglomerações produtivas em Portugal. $\mathrm{Na}$ quarta seção, detalhamos o cluster do calçado de Portugal, o que é o complexo industrial calçadista, sua localização, a descrição do mercado internacional de calçado, a estrutura produtiva portuguesa voltada ao calçado. Na quinta seção, apresentamos a entidade gestora, o funcionamento da governança e o Plano Estratégico do Cluster do Calçado 2014 2020. A sexta seção é reservada às considerações finais.

\section{Governança territorial como novo modo de cooperação e coordenação dos territórios para o desenvolvimento}

Utilizada por diferentes ciências, como a Ciência Política, a Administração, a Economia e a Geografia, a noção de governança tem significados distintos. Não se trata de um conceito novo, sendo originalmente empregado em trabalhos sobre as formas operacionais utilizadas para a coordenação de empresas ou firmas. Na década de 1980, o conceito foi aplicado em trabalhos do Grupo Banco Mundial sobre a capacidade administrativa dos Estados, nos quais foram elaboradas políticas, diretrizes e metas econômicas (e sociais) para os países subdesenvolvidos (Leloup, Moyart e Pecqueur, 2005; Pires et al., 2011).

A noção de governança também está presente no documento norteador das políticas europeias, o Livro Branco da Governança Europeia, publicado pela Comissão Europeia em 2001, com o objetivo de promover e ampliar o ambiente democrático na União, no qual são apresentados os instrumentos necessários para o estabelecimento de políticas mais coerentes nos países membros e os princípios (abertura, participação, responsabilização, eficácia, coerência e proporcionalidade) considerados basilares da democracia e do Estado Democrático de Direito e que podem ser aplicados a todos os níveis de governo, independentemente da estrutura territorial do Estado-membro (Comissão Europeia, 2001).

A noção de governança entendida no presente artigo, concebida enquanto um novo modo de cooperação e de coordenação dos territórios para o desenvolvimento, abrange as 
mudanças realizadas pelo processo de globalização, como a reestruturação produtiva e a reforma político-administrativa do Estado, as quais têm induzido a uma realocação de responsabilidades e de atuação de diferentes atores territoriais, tanto na escala de planejamento quanto na de ação. Elementos como a variedade de atores, a descentralização e a participação, o caráter democrático, a cooperação e a coordenação, são essenciais nesses novos modelos que se podem se manifestar de formas variadas, o que assinala a especificidade e a complexidade dos territórios.

A governança se encaixa no conjunto dos novos fatores de produção e, sendo o produto da organização local, apresenta-se como um fator de localização incomensurável, intransferível e tampouco quantificável. Para Vale (2009), com a evolução dos sistemas econômicos, o conhecimento passa a ocupar posição central dentre os fatores decisivos para o progresso tecnológico. A economia pós-fordista é menos dependência do trabalho e do capital e mais dependência do conhecimento, "fator indispensável para a competitividade das empresas e para o desenvolvimento das economias regionais e dos Estados-nação" (Vale, 2009, p. 10). Nesse contexto, a governança é um elemento essencial nas políticas públicas voltadas a P\&D, evidenciando a articulação dos atores territoriais mais diretamente envolvidos no desenvolvimento do território (Storper e Harrison, 1994).

Na tipologia de Benko e Pecqueur (2001), elaborada para caracterizar o conjunto de fatores sociais e culturais responsáveis pela diferenciação dos territórios, a governança territorial se encaixa tanto como ativo territorial quanto como recurso específico. $\mathrm{O}$ ativo territorial se deve ao ambiente cultural e industrial (atmosfera), a acumulação de conhecimentos tácitos (aprendizagem) e ao ambiente institucional favorável; o recurso específico se deve a mobilização institucional e organizacional adequada às estratégias locais (Pires et al, 2011).

Realizada essa breve introdução à problemática, apresentaremos as contribuições teóricas para fundamentar este artigo. É importante salientar que as contribuições selecionadas observam a governança em contextos urbanos (Chamusca, 2013; Fernandes e Chamusca, 2009; Ferrão, 2010; Carmo, 2014) e no âmbito produtivo (Storper e Harrisson, 1994; Vale e Cadeira, 2006; Pires et al, 2011; Fuini, 2015, Alcântara, 2017), de modo que o denominador comum para articular as diferentes contribuições é o reconhecimento de que a governança territorial aparece como uma forma de regulação do território e de interdependência dinâmica entre os agentes notadamente produtivos e as instituições locais. 
Ao analisar a realidade no contexto urbano, Chamusca (2013) concebe a governança como um processo flexível, híbrido e multifacetado de regulação. Esse processo implica no desenvolvimento de múltiplas formas de integração e de participação, na construção de estruturas e de atividades menos hierárquicas e burocráticas, no necessário reconhecimento das regras e das normas capazes de regular a ação coletiva e, por fim, na criação de mecanismos de aprendizagem e de adaptabilidade que permitam a adequada resolução de problemas comuns. Na mesma linha, Fuini (2010) destaca que a governança evidencia formas intermediárias de articulação entre atores sociais e que concebe tipos diferenciados de gestão, onde são manifestados interesses distintos e conflitantes entre os atores envolvidos, de modo que a busca pela convergência destes interesses é o que movimenta essa estratégia de desenvolvimento, que é, por natureza, parcial e provisória.

A governança territorial decorre de um processo no qual observamos a interação de cinco elementos, como apresentado na Tabela 1.

Tabela 1 - Características da Governança Territorial.

\begin{tabular}{|c|l|}
\hline $\begin{array}{c}\text { Elementos da } \\
\text { governança territorial }\end{array}$ & \multicolumn{1}{|c|}{ Características } \\
\hline Dinâmica territorial & $\begin{array}{l}\text { Conjunto de ações relacionadas ao processo de desenvolvimento, } \\
\text { empreendidas por atores/agentes, organizações/instituições de uma sociedade } \\
\text { identificada histórica e territorialmente. }\end{array}$ \\
\hline \multirow{3}{*}{ Bloco socioterritorial } & $\begin{array}{l}\text { Refere-se ao conjunto de atores localizados histórica e territorialmente que, } \\
\text { pela liderança que exercem localmente, assumem a tarefa de promover os } \\
\text { novos rumos do desenvolvimento do território por meio de concertação } \\
\text { público-privada. }\end{array}$ \\
\hline Concertação social & $\begin{array}{l}\text { Processo em que representantes das diferentes redes de poder socioterritorial, } \\
\text { por meio de procedimentos voluntários de conciliação e mediação, assumem a } \\
\text { prática da gestão territorial de forma descentralizada. }\end{array}$ \\
\hline socioterritorial & $\begin{array}{l}\text { Referem-se a segmentos da sociedade que são organizados territorialmente, } \\
\text { representados pelas suas lideranças, e que constituem a principal estrutura de } \\
\text { poder que, em cada momento da história, assumem posição hegemônica e } \\
\text { direciona, política e ideologicamente, o processo de desenvolvimento. }\end{array}$ \\
\hline Pactos socioterritoriais & $\begin{array}{l}\text { Referem-se aos acordos ou ajustes decorrentes da concertação social que } \\
\text { ocorrem entre os diferentes representantes de uma sociedade organizada } \\
\text { territorialmente e que está relacionada à definição do seu projeto de } \\
\text { desenvolvimento futuro. }\end{array}$ \\
\hline
\end{tabular}

Fonte: Fuini (2015).

A dinâmica territorial corresponde ao conjunto de ações efetivadas por diferentes atores em determinados territórios. Da existência e da necessária participação dos diferentes atores, temos a constituição do bloco socio-territorial, o qual vai resultar na formação das 
redes de poder do território. Do funcionamento do bloco, permeado por atritos e possibilidades de negociação, a concertação social objetiva a definição dos projetos políticos de desenvolvimento, isto é, o pacto socio-territorial. É da articulação dessas diferentes características que podemos observar a dinâmica do processo de desenvolvimento territorial. A governança é o resultado da organização e das estratégias, visando solucionar problemas específicos ancorados no território, não se tratando de um ambiente organizacional amistoso, pois a existência de um espaço de negociação entre atores de diferentes segmentos pressupõe a existência de antagonismos e conflitos intra e extraclasses (Dallabrida, 2017).

As estratégias de governança visam solucionar problemas característicos manifestados no território (Pires et al, 2011; Alcântara; 2017) e, ao considerar a multiplicidade de atores e a diversidade de interesses, podemos analisá-las com base em quatro diferentes tipos, como apresentado no Tabela 2.

Tabela 2 - Tipos de governança territorial

\begin{tabular}{|c|l|}
\hline Tipo & \multicolumn{1}{|c|}{ Características da governança } \\
\hline Privada & $\begin{array}{l}\text { São organizações privadas dominantes que impulsionam e pilotam dispositivos de } \\
\text { coordenação de recursos com objetivo de apropriação privada do território. }\end{array}$ \\
\hline Privada-coletiva & $\begin{array}{l}\text { O ator chave é uma organização formal que agrupa operadores privados e impulsiona a } \\
\text { coordenação de recursos e de estratégias. }\end{array}$ \\
\hline $\begin{array}{c}\text { Estatal-privada e } \\
\text { pública }\end{array}$ & $\begin{array}{l}\text { O Estado e as instituições públicas impulsionam a coordenação de recursos e de } \\
\text { estratégias territoriais com o setor privado. }\end{array}$ \\
\hline Pública-tripartite & $\begin{array}{l}\text { São instituições públicas, organizações privadas e da sociedade civil que, juntas, } \\
\text { impulsionam a coordenação compartilhada de recursos e estratégias territoriais. }\end{array}$ \\
\hline
\end{tabular}

Fonte: Pires et al (2017).

A partir do Tabela 2, podemos observar a forma de organização do território em prol do desenvolvimento e a existência ou não de outros atores territoriais, bem como apreender como se materializam as relações de poder na governança. O modelo ideal é o tripartite, mas isso não significa que não exista um ator principal, no qual os outros atores têm atuação variável de acordo com a forma de interação e a estrutura de governança que é preferível, isto é, que atenda a princípios que garantam o efetivo funcionamento.

As novas estratégias de desenvolvimento mostram a importância da construção de um território de base local por meio da articulação entre diferentes atores, mas que não deve se isolar do contexto global. As estratégias de desenvolvimento territorial possuem caráter 
mais difuso e são sustentadas por fatores não apenas econômicos, mas também sociais, culturais e territoriais (Leloup, Moyart e Pecqueur, 2005; Vale e Caldeira, 2006), podendo ser observados em diferentes recortes geográficos e setoriais (Pires et al 2011).

O apoio proveniente dos gestores públicos locais ou regionais, além da convicção do papel a desempenhar no fomento econômico do território, figura como um fator fundamental nas iniciativas de desenvolvimento local/territorial. Isso requer a reformulação das funções que as diferentes administrações públicas territoriais devem desempenhar, tendo como objetivo negociar, com os atores locais, a construção de um entorno institucional que beneficie o território, como, por exemplo, apoiando o empresarial, composto por micro, pequenas e médias empresas (MPMEs) (Pires et al, 2011; Vale e Caldeira, 2006).

Considerando que o desenvolvimento está vinculado a um modelo territorial e a um ordenamento do território, é fundamental reconhecer o impacto que uma estratégia de desenvolvimento pode incidir sobre o território. É necessário que seja evidenciado os atributos ou as carências para que as estratégias de desenvolvimento sejam elaboradas e implementadas da melhor forma a atender as demandas sociais locais e regionais. Enquanto processo que envolve a mobilização de atores, recursos e instituições com forte vínculo espacial e capazes de constituir um canal de articulação multiescalar, o desenvolvimento territorial busca alavancar a competitividade das atividades econômicas locais e propiciar bem-estar social e cultural à comunidade que vive nesse meio. Essa nova dimensão do desenvolvimento se apresenta como um produto da iniciativa compartilhada, o qual delega uma postura ativa à sociedade que compõe aquele local ou território, e, com isso, exerce o papel de agente transformador e não apenas de beneficiária do desenvolvimento (Pires et al, 2011).

A questão levantada no debate do desenvolvimento territorial é mostrar a potencialidade de se efetivar processos de mobilização entre atores, instituições e recursos em prol do desenvolvimento, tendo, assim, a centralidade da governança territorial enquanto recurso necessário. Com isso, ao ser considerado um modo inédito de organização territorial, a governança tem enfatizado a configuração de um novo paradigma do planejamento do desenvolvimento e que, em Portugal, tem ganhado visibilidade, como, por exemplo, nas políticas urbanas (Fernandes e Chamusca, 2009, Chamusca, 2013), nos planos destinados ao ordenamento do território (Carmo, 2014) e em espaços produtivos tradicionais no país, 
como a produção de vinho (Alcântara, 2017) e o cluster do calçado português, estudo de caso desse artigo.

\section{A definição de cluster e as políticas de apoio as aglomerações produtivas em Portugal}

Nos Estados Unidos, Porter (1998), a partir de estudos sobre as condições e as vantagens competitivas em aglomerados produtivos, constatou que as aglomerações podem assumir o papel de instrumentos de dinamização econômica, contribuindo para o aumento das exportações e possibilitando a constituição de um espaço de diálogo entre empresas, órgãos governamentais e outras instituições que colaboram para ampliar a competitividade. Denominando essas aglomerações produtivas de clusters, Porter (1998) os concebeu como forma de promoção da competitividade do território por meio de uma eficiente organização/inter-relação dos recursos e dos atores locais.

No Brasil, os estudos sobre aglomerações produtivas levaram ao desenvolvimento da ideia de Arranjo Produtivo Local (Lastres e Cassiolato, 2003). Na Europa, destacam-se duas terminologias: na Itália, os distritos industriais (Becattini, 1994) e na França, o sistema produtivo localizado (Courlet, 2013). Essas definições compartilham, como traços comuns, a aglomeração de empresas de uma mesma cadeia produtiva com um rol variado de atores, resultando em um ambiente de cooperação e que demanda um mecanismo de regulação, a governança (Lastres e Cassiolato, 2004; Fuini, 2015; Storper e Harryson, 1994).

Em Portugal não foi criado um termo próprio para aglomerações produtivas, de modo que foi adotado, nas políticas públicas, a terminologia porteriana, ou seja, os clusters. É importante destacar que os diferentes termos remetem a um mesmo fenômeno geográfico e que tem sido considerado, por lideranças políticas e intelectuais do campo do desenvolvimento, como importante instrumento de dinamização econômica do território.

O estudo "Construir vantagens competitivas em Portugal", coordenado por Porter na década de 1990, foi a primeira iniciativa do governo português para o apoio as aglomerações produtivas (industriais ou focada na oferta de serviços), o qual tinha como 
objetivo identificar os setores de Portugal que apresentavam vantagens competitivas e quais os desafios apresentados para o seu efetivo desenvolvimento.

Cunhado por Porter e amplamente conhecido na literatura econômica e geográfica, os elementos utilizados para o estudo estão assentados no modelo do diamante. Seis clusters prioritários (o vinho, o turismo, a madeira, o vestuário, o calçado e o automóvel) foram identificados, mas, em decorrência de questões políticas, o estudo não foi implementado.

Sobre as políticas destinadas aos clusters, Chorincas (2009) e Ferreira, Natário e Braga (2018), nos informam que, durante a primeira década dos anos 2000, diferentes iniciativas foram propostas pelo governo federal português, como o Programa Integrado de Apoio à Inovação (PROINOV), o Programa de Recuperação de Áreas e setores Deprimidos (PRASD), o Programa Nacional de Ação para o Crescimento e o Emprego (PNACE) e o Plano Tecnológico.

O Programa Integrado de Apoio à Inovação (PROINOV), enquadrado na Agenda para a Inovação em Portugal, teve como objetivo o desenvolvimento de clusters de inovação em áreas-chave de atividades com tradição na especialização e na internacionalização. A colaboração entre empresas, a participação de associações empresariais e de instituições de ensino, pesquisa e inovações, além do setor financeiro, eram critérios necessários. No PROINOV, estudos nos setores de automóvel, software e calçados foram realizados, mas não tiveram continuidade devido às alterações no ciclo político.

O Programa de Recuperação de áreas e setores deprimidos (PRASD) buscou elaborar estratégias empresariais e orientar o poder público na dinamização da economia e alocar as ações do Estado em áreas não atendidas pelo mercado (Chorincas, 2009). O Programa Nacional de Ação para o crescimento e o Emprego (PNACE), com foco na competitividade e no empreendedorismo, estimulou o estabelecimento de parcerias e a dinamização de clusters com perfil de atuação internacional. O Plano Tecnológico, responsável por oferecer uma estratégia de crescimento e de competitividade com base nos novos fatores produtivos (conhecimento, tecnologia e inovação), buscou articular empresas, centros de formação e pesquisa, com o intuito de potenciar sinergias em redes de projetos comuns (Chorincas, 2008; Ferreira, Natário e Braga, 2018). 
Segundo o documento "Estratégias de Eficiência Coletiva" (EEC), desenvolvido por Chorincas (2009) para o Quadro de Referência Estratégico Nacional (QREN), todas as iniciativas mencionadas não lograram resultados satisfatórios. Além de ser um alerta aos problemas encontrados nas políticas destinadas aos clusters, o documento também apresentou um material de referência para a identificação de economias de aglomeração, de proximidade ou de escala a partir de um conjunto de critérios que visa à inovação, à qualificação e à modernização das empresas inter-relacionadas em determinado território, além do estímulo à cooperação e ao funcionamento em rede entre empresas e instituições de pesquisa, desenvolvimento e inovação (Chorincas, 2009). No documento foram apresentados um conjunto de critérios que permitem identificar cinco fatores críticos (Tabela 3), os quais podem resultar no sucesso ou no insucesso das estratégias.

Tabela 3 - Fatores que podem resultar no sucesso ou no insucesso das estratégias

\begin{tabular}{|l|l|}
\hline \multicolumn{1}{|c|}{ Critério } & \multicolumn{1}{c|}{ Descrição } \\
\hline $\begin{array}{l}\text { Consistência } \\
\text { da rede }\end{array}$ & $\begin{array}{l}\text { A natureza e a variedade dos atores que integram o cluster, considerando a necessidade } \\
\text { que esses atores cubram a complexidade dos domínios de intervenção ou ações } \\
\text { necessárias. Essa consistência envolve o nível de articulação entre os atores. }\end{array}$ \\
\hline $\begin{array}{l}\text { Abrangência } \\
\text { da rede }\end{array}$ & $\begin{array}{l}\text { Considera a natureza e a dimensão das atividades que podem ser impulsionadas pelo } \\
\text { cluster, a articulação entre setor e território, destacando a sua capacidade de indução, de } \\
\text { inovação e as possíveis articulações com clusters de outros países. }\end{array}$ \\
\hline $\begin{array}{l}\text { Consistência } \\
\text { da estratégia e } \\
\text { do Programa } \\
\text { de Ação }\end{array}$ & $\begin{array}{l}\text { Garantia da coerência das estratégias assumidas para cluster nos documentos de } \\
\text { enquadramento nacional (português) e regional (União Europeia) para o setor produtivo } \\
\text { em questão. É importante que as estratégias contemplem uma reflexão dos atores } \\
\text { envolvidos no que tange ao diagnóstico do cluster, considerando as suas forças, } \\
\text { fraquezas, oportunidade e ameaças. }\end{array}$ \\
\hline $\begin{array}{l}\text { Ambição e } \\
\text { resultados }\end{array}$ & $\begin{array}{l}\text { É preciso que a entidade gestora do cluster mantenha um sistema de análise crítico e o } \\
\text { acompanhamento dos resultados e dos impactos, que devem ser estendidos a todos os } \\
\text { atores envolvidos. }\end{array}$ \\
\hline $\begin{array}{l}\text { Modelo de } \\
\text { governação }\end{array}$ & $\begin{array}{l}\text { Todos os atores devem estar representados na governação do cluster, sendo que a sua } \\
\text { possível ineficácia pode resultar na desmobilização da visão comum que deve ser } \\
\text { compartilhada. O modelo deve prever as regras de funcionamento que garantam a } \\
\text { continuidade, bem como a legitimidade do modelo em situações de conflito. }\end{array}$ \\
\hline
\end{tabular}

Fonte: Chorincas (2009).

Elaboração: José Renato Ribeiro.

Dentre os critérios, destacamos, no presente artigo, o critério "Modelo de governança" como central para o bom desenvolvimento das estratégias e, consequentemente, dos clusters. A essencialidade da governança também é identificada no documento "Regulamento de Reconhecimento dos Clusters de competitividade", publicado no Diário da República de 23 de março de 2015. O documento é o mais recente marco de orientação para os clusters no país e visa estimular as iniciativas estratégicas de eficiência coletiva, reforçando a competitividade, a promoção da inovação e o estímulo à internacionalização. 
Estabelecer uma visão estratégica e um programa de ação capaz de gerar impactos na economia (desenvolvimento econômico, geração de emprego e renda, capacidade exportadora e internacionalização) são as condições necessárias para a apresentação das propostas de reconhecimento. Dentre as características que os clusters devem apresentar, assinalamos o disposto na alínea $c$.

Cooperar e funcionar em rede, envolvendo empresas e outros operadores relevantes para a valorização dos sectores ou cadeias de valor, nomeadamente entidades não empresariais do SI\&I, de formação profissional, associações empresariais e entidades públicas no sentido de garantir a maximização das oportunidades de participação cruzada. (DIÁRIO DA REPÚBLICA, 2015, p. 7075)

A existência de diferentes atores (empresas, entidades científicas e profissionais, associações empresarias e entidades públicas) nos permite identificar a necessidade de um mecanismo de governança. Com o reconhecimento aprovado, os clusters podem pleitear apoios públicos para a dinamização de suas atividades. As condições gerais para o reconhecimento dos clusters estão no artigo 50 do regulamento, o qual é apresentado, na íntegra, no Tabela 4.

De acordo com o regulamento, há dois os tipos de clusters (consolidados e emergentes). Os clusters consolidados apresentam grande abrangência, alto nível de inovação, amplo impacto econômico nacional e capacidade exportadora. Já os clusters emergentes são aqueles que revelam dinâmicas novas de crescimento em áreas estratégicas e que, por isso, permitem projetar um grau de influência crescente na economia nacional.

A avaliação das candidaturas e a responsabilidade sobre o processo de reconhecimento é atribuída a Comissão de Avaliação, grupo composto pela Agência para a Competitividade e Inovação (IAPMEI), entidade que preside a comissão, pelo Gabinete de Estratégia e Estudos do Ministério da Economia, pela Agência para o Desenvolvimento e Coesão, pela Agência Nacional de Inovação, pela Agência para o Investimento e Comércio Externo de Portugal e pelo Programa Operacional Competitividade e Internacionalização. Essa articulação de diferentes entidades públicas responsáveis pela dinamização econômica de Portugal é necessária por se tratar de uma iniciativa multi-institucional, como observado no Tabela 5. 
Tabela 4 - Condições gerais para o reconhecimento dos clusters de competitividade

a) A missão, fins, objetivos, metas, indicadores de desempenho, bem como a lógica de agregação do cluster sejam enquadráveis nos objetivos do presente despacho;

b) A abrangência territorial da atividade económica dos membros associados seja feita por referência às cadeias de valor inerentes das atividades nucleares e de suporte;

c) Estarem integrados numa rede de parceiros com representatividade nas áreas sectoriais, das cadeias de valor ou temáticas relevantes, como sejam empresas, associações empresariais, entidades públicas e instituições de suporte que possam contribuir para a realização dos objetivos do presente despacho;

d) Possuírem uma composição e gestão equilibradas não permitindo a existência de uma posição dominante dentro do cluster;

e) Apresentarem uma matriz de competências e valências do cluster fundamentada e adequada aos objetivos pretendidos e metas a atingir;

f) Apresentarem uma estrutura com a seguinte composição: i. Empresas associadas com uma representatividade de, pelo menos, $60 \%$ do número total de associados e entidades não empresariais do SI\&I, com uma presença mínima de 3 entidades associadas que demonstrem uma diversidade de áreas de conhecimento; ii. Outras entidades relevantes para o processo de clusterização, nomeadamente associações empresariais.

g) Revestirem a forma de associação, sem fins lucrativos, que cumpra o seguinte: i. Estar legalmente constituída no limite até à data da celebração do contrato-programa previsto no artigo 15.o; ii. Assegurar a equilibrada representação nos órgãos sociais de empresas, associações empresariais e entidades do SI\&I; iii. Assegurar na direção do cluster uma representação maioritária das empresas associadas; iv. Apresentar um quadro de recursos humanos com competências adequadas e afetação necessária ao cumprimento do programa de ação e à prossecução da missão do cluster.

h) Apresentarem um programa de ação descritivo da estratégia de atuação do cluster, para o período de reconhecimento, elaborado nos termos do Anexo ao presente regulamento, que veicule informação que permita fundamentar o posicionamento do cluster no que respeita ao desenvolvimento dos seus diferentes vetores estratégicos.

Fonte: Adaptado de Diário da República, Despacho n. 2909/2015, p. 7075.

Tabela 5 - Objetivo institucional dos órgãos responsáveis pela avaliação das candidaturas

\begin{tabular}{|l|l|}
\hline \multicolumn{1}{|c|}{ Entidade / Instituição } & \multicolumn{1}{c|}{ Objetivo/missão institucional } \\
\hline $\begin{array}{l}\text { Agência para a } \\
\text { Competitividade e Inovação } \\
\text { (IAPMEI) }\end{array}$ & $\begin{array}{l}\text { Promover a competitividade e o crescimento empresarial; assegurar o } \\
\text { apoio à concessão, execução e avaliação de políticas dirigidas à atividade } \\
\text { industrial, visando o reforço da inovação, do empreendedorismo e do } \\
\text { investimento empresarial. }\end{array}$ \\
\hline $\begin{array}{l}\text { Gabinete de Estratégia e } \\
\text { Estudos do Ministério da } \\
\text { Economia (GEE) }\end{array}$ & $\begin{array}{l}\text { Prestar apoio técnico, aos responsáveis pelo Ministério da Economia, na } \\
\text { definição da política económica e no planejamento estratégico, por meio } \\
\text { do desenvolvimento de estudos, coleta e tratamento de dados. }\end{array}$ \\
\hline $\begin{array}{l}\text { Agência para o } \\
\text { Desenvolvimento e Coesão } \\
\text { (ADCoesao) }\end{array}$ & $\begin{array}{l}\text { Coordenar a Política de Desenvolvimento Regional e assegurar a } \\
\text { coordenação dos Fundos Europeus Estruturais e de Investimento (FEEI). }\end{array}$ \\
\hline $\begin{array}{l}\text { Agência Nacional de Inovação } \\
\text { (ANI) }\end{array}$ & $\begin{array}{l}\text { Promover a valorização do conhecimento por meio da colaboração e } \\
\text { articulação entre empresas e SCTN. }\end{array}$ \\
\hline $\begin{array}{l}\text { Agência para o Investimento e } \\
\text { Comércio Externo de Portugal } \\
\text { (AICEP) }\end{array}$ & $\begin{array}{l}\text { Promover a internacionalização das empresas portuguesas e apoiar sua } \\
\text { atividade exportadora. }\end{array}$ \\
\hline $\begin{array}{l}\text { Programa Operacional } \\
\text { Competitividade e } \\
\text { Internacionalização (COMPETE } \\
\text { 2020) }\end{array}$ & $\begin{array}{l}\text { Contribuir para a criação de uma economia mais competitiva, baseada } \\
\text { em atividades intensivas em conhecimento, em bens e serviços } \\
\text { transacionáveis ou internacionalizáveis e no reforço da qualificação e da } \\
\text { orientação exportadora das empresas portuguesas. }\end{array}$ \\
\hline
\end{tabular}

Fonte: Elaborado a partir dos sites das entidades ${ }^{1}$.

1 IAPMEI: https://www.iapmei.pt/; GEE: https://www.gee.gov.pt/pt/o-gee/legislacao; ADCoesao: http://www.adcoesao.pt/; ANI: https://ani.pt; AICEP: http://www.portugalglobal.pt/PT/Paginas/Index.aspx; https://www.portugal2020.pt/Portal2020/programas-operacionais-portugal-2020-2. 
Para a avaliação, são considerados o cumprimento das condições para o reconhecimento do cluster (condições apresentadas no Tabela 3), o mérito do programa de ação e a estrutura de governança apresentada. Quem efetivamente avalia é a IAPMEI, responsável por elaborar um relatório de análise que deve ser apreciado pela Comissão de Avaliação. Em posse do resultado da avaliação, a IAPMEI, após requerer a audição dos interessados, submete o relatório final à apreciação dos representantes do governo no campo econômico, do desenvolvimento regional e dos setores no qual o cluster está inserido. É esse representante do governo quem decide pelo reconhecimento, de modo que a IAPMEI deve notificar o cluster em questão.

Após aprovado, as entidades gestoras (representantes oficiais dos clusters) celebram, com a IAPMEI, um contrato-programa que estabelece o prazo de vigência de seis anos, o qual pode ser prorrogado por um ano, e no qual constam as circunstâncias para a revogação do referido status de cluster de competitividade: a) descumprimento dos compromissos firmados no programa de ação e no contrato-programa; b) mudanças dos pressupostos que conduziram ao reconhecimento do cluster; c) apresentação de informações enganosas sobre a situação das entidades envolvidas.

Destacamos que, além de apresentar o objetivo do regulamento e de especificar quais são e em que condições devem estar estabelecidos os clusters, o documento em questão prevê especial atenção ao bom funcionamento da entidade gestora que pode repercutir diretamente no cluster. Essa preocupação se estende também a proposição de mecanismos de acompanhamento, monitorização e avaliação dos aglomerados, bem como a eventual perda do reconhecimento, o que se traduz como uma possível punição.

O processo de reconhecimento terminou em 2017 com a identificação de 19 clusters em setores diversos e com diferenciado grau de emprego tecnológico: Indústrias da Fileira/cadeia Florestal (setor madeireiro), AEC - Arquitetura, Engenharia e Construção (construção civil), AED Cluster (aeroespacial e defesa), Plataforma Ferroviária Portuguesa (logística e transporte), Vinha e do Vinho (bebida), Petroquímica, Química Industrial e Refinação (petróleo e derivados), Calçado e Moda (calçadista), Mar Português (multisetorial - pesca, indústria naval e portos), Recursos Minerais de Portugal (mineração), Habitat Sustentável (agregados reciclados), Cluster Smart Cities Portugal (soluções urbanas 
inteligentes e integradas), Têxtil: Tecnologia e Moda (têxtil e vestuário), Engineering \& Tooling (engenharia), Health (complexo da saúde), MOBINOV (automóveis), AgroFood (alimentar), PRODUTECH - Polo das Tecnologias de Produção (tecnologia de produção), TICE (tecnologias da informação) e Turismo (serviços turísticos).

Os clusters reconhecidos abrangem aqueles identificados por Porter no estudo encomendado pelo governo nos anos de 1990, o que atesta a relevância das aglomerações produtivas para a economia portuguesa outrora identificadas. Além disso, o reconhecimento realizado por meio das EECs do QREN atribuiu maior expressão à política de clusters, servindo como "um instrumento fundamental de integração operacional de prioridades estratégicas relativas ao reforço da cooperação, ao robustecimento da inovação e da I\&D, e ao aumento da projeção internacional" (Moreira, 2014, p. 30).

Um dado importante identificado por Moreira (2014), ao analisar a política de clusters apresentadas no quadro das EECs, está nas diferentes lógicas de ajustamento territorial que foram evidenciadas pelos clusters identificados. Essas lógicas apresentam relação entre a incidência regional do investimento em projetos associados e a concentração espacial dos setores. Dessa pesquisa, o autor afirma que há um descompasso, um desequilíbrio entre o investimento realizado, os atores envolvidos e o número de empresas abarcadas. Para tanto, o autor (2014, p. 102) chama atenção para a "necessidade da existência de esforços estratégicos direccionados para a qualidade da abrangência das redes de actores, que idealmente devem incluir um bom número de empresas líderes e uma boa extensão de empresas mais pequenas", o que possibilitaria que um maior número de atores fosse beneficiado pelas medidas de melhoramento de produtividade e do próprio ambiente socioterritorial decorrente das estratégias de governança.

De acordo com a IAPMEI ${ }^{2}$, com base em dados de 2013, a representatividade dos clusters para a economia portuguesa pode ser observada nos números apresentados na dimensão empresarial, associativa e econômica. Na dimensão empresarial são 1.815 empresas envolvidas (o turismo não está incluído), no qual 63\% são pequenas e médias empresas, 20\%, microempresas e 17\%, grandes empresas. Na dimensão associativa são 2.245 associações, sendo que $81 \%$ são empresas, $11 \%$ são entidades envolvidas na pesquisa e

\footnotetext{
${ }^{2}$ Representatividade nacional - IAPMEI - https://www.iapmei.pt/Paginas/Representatividade-nacional.aspx.
} 
inovação, 4,3\% são associações empresarias e os restantes, 3,7\%, são outros associados. Por fim, na dimensão econômica há 165.374 trabalhadores inseridos nas empresas associadas, um volume de negócios por volta dos 44,780 M€ (44,7 milhões de euros), Valor Acrescentado Bruto de 12.139 $\mathrm{M} €$ (12,1 milhões de euros), exportações que atingem a cifra de 15.155 M€ (15,1 milhões de euros) e importações de 6.576 M€ (6,5 milhões de euros).

Após essa apresentação sobre as principais iniciativas de apoio aos clusters em Portugal, avançamos para a análise sobre o caso do cluster do calçado de Portugal. Para tanto, é importante uma breve apresentação do setor calçadista a partir de relatórios disponibilizados pela Associação Portuguesa dos Industriais de Calçado, Componentes, Artigos de Pele e seus Sucedâneos (APICCAPS).

\section{0 cluster de calçados de Portugal}

Considerado um setor dinâmico e de grande importância para o desenvolvimento econômico português, a produção de calçados está concentrada na região norte de Portugal e pode ser agrupada em duas principais zonas: uma composta pelos concelhos de Felgueiras e Guimarães (localizados nos distritos do Porto e de Braga, respectivamente); a outra, por Santa Maria da Feira, São João da Madeira e Oliveira de Azeméis (todos no distrito de Aveiro). O concelho de Alcabaça, no distrito de Leiria, também é listado como importante produtor do cluster, sobretudo na produção de artigos de pele (APICCAPS, 2017; Carmo, 2014; Santo, 2015). Na figura 1, temos a distribuição das empresas de calçados sócias da APICCAPS, de acordo com o seu respectivo distrito.

Segundo Carmo (2014), os concelhos de Felgueiras e de São João da Madeira concentram o maior número de unidades produtivas, mas apresentam características distintas. No caso de Felgueiras, é observada uma estrutura industrial com unidades produtivas de maior dimensão, equipamentos e tecnologias mais avançadas e os empresários do setor apresentam um evidente espírito empreendedor. Com a utilização de tecnologias mais desenvolvidas, o emprego de mão de obra é menos intensivo, o volume da produção diária é alto e a qualidade do produto é baixa. 




Figura 1 - Localização das Empresas de Calçados Sócias da APICCAPS Fonte: Santo, 2015, p. 57.

Com uma produção antiga, São João da Madeira possui uma produção tradicional de calçados, com sua primeira indústria em 1933. As unidades industriais são, em grande maioria, de dimensões menores e com emprego tecnológico e de equipamentos menos avançados. Diferentemente de Felgueiras, o emprego de mão de obra é mais intensivo e o volume produzido diariamente é baixo, com produtos de alta qualidade e preços elevados. Se em Felgueiras temos a produção de calçados de homens considerados informais, com o preço mais baixo e que atende a segmentos inferiores do mercado externo, em São João da Madeira temos calçados de senhoras e de homens considerados formais, com preço mais elevado e que atende a segmentos superiores do mercado externo.

O cluster do calçado português envolve um complexo industrial composto por três tipos de indústria: fabricação de calçados, componentes para calçados e artigos de pele. Antes de trazermos informações e dados recentes em relação ao cluster, é necessário um breve retrospecto sobre a formação de uma das atividades industriais mais tradicionais do país. 
Embora a primeira unidade produtiva de calçado tenha surgido em São João da Madeira em 1933, vamos acompanhar Santos (2015) e Loureiro, Santo e Sarmento (2017), que estabelecem três períodos para descrever a evolução do cluster. O primeiro período se estende de 1974 a 1993 e se caracteriza pelo crescimento do aglomerado baseado no cliente. Esse período é marcado por um cenário confortável, motivado pela abundância de encomendas destinadas ao centro e ao norte da Europa. Os fatores competitivos eram os baixos custos de produção, os incentivos estatais e a boa localização geográfica, fatores que tornavam Portugal um destino para investimentos, como a instalação de plantas fabris de marcas internacionais de grande dimensão. A mão de obra possuía baixo nível de qualificação e as políticas de apoio eram focadas no aproveitamento de economias de escala conferidas pela produção em massa, desprovidas de inovação tecnológica e de gestão criteriosa, mas aproveitando-se da política monetária expansionista que o país adotara. Segundo Santos (2015), em 1974 eram 673 empresas e mais de 15 trabalhadores e ao fim do período, em 1994, o cluster era composto por 1.628 empesas e quase 60 mil trabalhadores.

O segundo período se estende de 1994 a 2006 e se caracterizou pela alteração do perfil competitivo em escala planetária. A década de 1990 é marcada pela intensificação do processo de reestruturação produtiva, ocasionado pelo colapso do modelo fordista, resultado da confluência de fatores de ordem interna (saturação do mercado e a descentralização espacial decorrente em resposta à militância operária) e de ordem externa (capacidade concorrencial da indústria japonesa que adentra nos mercados domésticos das economias dos Estados Unidos e da Europa Ocidental). A resposta à concorrência industrial foi uma reestruturação industrial intensificada junto a uma racionalização nos países centrais, levando ao fechamento de fábricas, mais descentralização e maior desemprego. Nesse processo, os países do sudeste asiático, ao apresentarem fatores de produção mais competitivos, em especial, a mão de obra barata, foram o foco da deslocalização de linhas produtivas. Apesar da economia portuguesa apresentar fatores de produção tradicionais com os custos mais baixos da Europa, não foi capaz de competir com o cenário apresentado pela Ásia.

A indústria de calçado em todo o mundo não ficou alheia a esse processo. No caso de Portugal, Santo (2015) informa que grandes produtores internacionais de calçados, que 
outrora aproveitaram as vantagens de custo oferecidas pela economia portuguesa, passam a se beneficiarem das vantagens de custo muito assinaláveis das economias asiáticas, transferindo a planta fabril. Com a configuração desse novo cenário global, a indústria portuguesa de calçados reconhece a ineficiência de manter as estratégias até então adotadas, ou seja, os baixos custos de produção. Continuar nesse rumo levaria a indústria ao fracasso, uma vez que, com a oferta de mão de obra mais barata, a indústria asiática conseguia produzir lotes de maior dimensão a um custo menor.

Frente ao cenário apresentado e reconhecendo as novas perspetivas econômicas evidenciadas pela reestruturação produtiva, a indústria calçadista portuguesa iniciou um ambicioso processo estrutural de modernização do cluster com base em quatro pilares: utilização de métodos de gestão modernos, up-grade tecnológico, qualificação da mão de obra e uma forte dinâmica comercial baseada no design, na moda e na qualidade dos produtos. Como bem salienta Santo (2015, p. 38), "como qualquer mudança estrutural, revelou-se gradual, obrigou o sector a passar por períodos conturbados e só obteve os frutos dessa aposta anos mais tarde".

Se estendendo de 2007 a 2014, o terceiro período contempla o crescimento dos fatores competitivos na vertente imaterial. Apesar deste período coincidir com a crise financeira que assolou a economia portuguesa, e de outros países europeus, afetando muitas indústrias, o setor de calçados não foi fortemente prejudicado. Esse dado positivo e distinto de outras indústrias pode ser observado por meio das exportações que registraram aumento.

Para Santo (2015), Loureiro, Santo e Sarmento (2017) e Silva (2019), o bom desempenho da indústria portuguesa de calçados no período de crise se deve aos investimentos realizados na fase anterior, pautada na modernização do cluster e que, sem abandonar um aspecto importante da história do calçado português (os modelos de produção artesanal), optou por uma especialização direcionada para o calçado de maior valor (Loureiro, Santo e Sarmento, 2017; Silva, 2019).

Depois desse breve retrospecto, damos continuidade à análise do cluster a partir dos dados e das referências relativamente recentes sobre a situação do aglomerado. Segundo a Monografia Estatística de 2017, elaborada pela APICCAPS, a estrutura produtiva do cluster 
é composta majoritariamente por empresas de pequeno porte, uma característica marcante na estrutura empresarial portuguesa e especialmente na região norte do país. De um total de 1.875 empresas que compõem o aglomerado, cerca de $49 \%$ são microempresas, $39 \%$ são pequenas, $11 \%$ são médias e $1 \%$ são empresas de grande porte (equivalente a 11 empresas).

Ao considerar a situação de cada segmento do cluster, na indústria dos artigos de pele, a maioria é de microempresas $(75,8 \%)$, seguida das pequenas $(20,8 \%)$, médias $(2,5 \%)$ e grande (0,8\%). Na indústria voltada para a fabricação de calçado, de um universo de 1.475 empresas, $46,5 \%$ são empresas de micro porte, $40,7 \%$ são de pequeno porte, $12,2 \%$ são de médio porte e apenas $0,6 \%$ são grande porte. Na indústria dos componentes, temos a microempresa com $54,3 \%$ das empresas, a de pequeno porte com $37,1 \%$, a de médio com $8,2 \%$ e a de grande porte com $0,4 \%$.

Se as empresas de micro e pequena dimensão somam a maioria no número de estabelecimentos, no número de empregos o cenário é diferente. No caso da fabricação de calçados, mais da metade (55\%) dos trabalhadores estão em médias e grandes empresas; nas pequenas, temos $37 \%$ dos trabalhadores e os $8 \%$ restantes, nas microempresas. $\mathrm{Na}$ indústria dos componentes para calçado, as micro são responsáveis por $17 \%$, as pequenas por $43 \%$, as médias por $37 \%$ e apenas uma empresa de grande porte, é responsável pelo restante do total de empregos. Na indústria dos artigos de pele, a distribuição dos trabalhadores por porte da unidade produtiva apresenta maior equilíbrio (APICCAPS, 2017).

Sobre a produção oferecida pelo cluster, é observada uma variedade de calçados: calçados de segurança, desportivos, calçados de couro e de outros materiais, mas são os de couro que são o carro-forte do aglomerado. Nesse contexto, o couro é o principal produto na fabricação do calçado português ( $80 \%$ dos pares produzidos no ano de 2016), o que podemos caracterizar como uma especialização intra-industrial.

O principal tipo de calçado produzido pelo cluster é o de senhora (mais de $40 \%$ dos pares), seguido pelo de homem (um terço do total produzido) - ambos tendo o couro como material primordial. O destaque destes tipos de calçados está representado na quantidade produzida e no valor correspondente, visto que, em 2016, o cluster português produziu 82 
milhões de pares de calçado e mobilizou quase 40 mil trabalhadores, tendo a produção dominada pelos calçados de senhora e de homem, que representaram dois terços dos pares produzidos e mais de três quartos do seu valor.

O principal destino da produção do cluster é o mercado externo e, embora a China seja a maior produtora e exportadora de calçados do mundo, a produção portuguesa não compete diretamente com a chinesa devido a especificidade do produto. A China garante um produto mais competitivo no mercado mundial de calçados devido ao baixo custo da produção e na quantidade elevada de itens produzidos, o que não se verifica nos países europeus. No entanto, é no tipo de produto oferecido que está a vantagem competitiva. A produção chinesa é de calçados de baixa gama, ou seja, calçados baratos e de menor qualidade, já o calçado português é feito sob demanda, o que o caracteriza por apresentar resposta rápida e oferecimento de séries pequenas, competindo com o calçado italiano. Além disso, como observado no caso da produção em São João da Madeira, a produção é voltada aos calçados de senhoras e de homens considerados formais, com preço mais elevado e que atende a segmentos superiores do mercado externo (Silva, 2019).

Outra vantagem competitiva apresentada pelo produto português é a existência do bloco europeu. A proximidade geográfica e organizacional é um elemento positivo à competitividade do produto. A União Europeia possui nove países na lista dos 15 maiores exportadores, com destaque para a Itália (maior exportador europeu e segundo do mundo), seguida da Alemanha. A produção portuguesa figura na 13a posição, mas essa colocação, distante dos maiores produtores, esconde a especialização da indústria do calçado português (o calçado de couro), no qual o país tem destaque como 7o exportador mundial e o 3o exportador europeu, atrás da Itália e da Alemanha (APICCAPS, 2017). Segundo dados da APPICAPS (2017), 80\% da produção portuguesa é exportada para a Europa, podendo ser afirmado que a indústria calçadista nacional possui forte vocação exportadora (Carmo, 2014; Santo, 2015).

Em relação à importação, o protagonismo, se considerado o conjunto dos países, é da União Europeia, que, em 2016, importou 48\% das importações mundiais de calçado. A América do Norte e a Ásia importaram $28 \%$ e 19\%, respectivamente. Sobre a origem das importações da União Europeia, a APICCAPS assinala a participação do intra-bloco e da China. 
É curioso observar que, devido justamente ao tipo do calçado produzido (calçado de couro e que possui valor agregado mais elevado e que atende aos mercados mais exigentes e de maior rendimento médio), o mercado interno, ou seja, o consumidor residente em Portugal, tem a sua demanda atendida pela importação de calçados, em especial, calçados espanhóis e chineses, que são calçados produzidos com outros materiais e de valor reduzido (Carmo, 2014). Segundo a APICCAPS, a qualidade é o elemento distintivo do calçado português, que só é garantido pela proximidade geográfica entre o produtor de calçado e os fornecedores de componentes, o que nos permite considerar a importância da proximidade organizacional oferecida pela coordenação da Associação e a participação de outros players. Ao reconhecer a grande representação da indústria calçadista para a economia portuguesa, envolvendo uma cadeia produtiva (fileira) completa, é preciso considerar a relevância de um conjunto de atores que possibilitam a sua dinamização (Santos, 2018). Analisar a importância de um cluster para a dinâmica regional e nacional requer que observamos todo o aparato socioprodutivo e institucional envolvido. Nesse sentido, voltando à literatura consultada, os clusters são identificados por apresentarem, como condições essenciais, a concentração geográfica da produção, a existência de uma complexa rede de relações formais e informais (relações comerciais e produtivas, dentre elas a subcontratação) e de relações de compartilhamento de informação e conhecimento. Além disso, a literatura chama atenção para a existência de um tecido institucional de suporte próprio e constituído por associações empresariais, centros de tecnologia e formação profissional (centros de P\&D) (Santos, 2018; Vale, 2009).

O tecido institucional do cluster é composto pela Agência para a Competitividade e Inovação (IAPMEI), pela Agência Nacional de Inovação (ANI) e pela Agência para o Investimento e Comércio Externo de Portugal (AICEP), três entidades participantes do "Regulamento de Reconhecimento dos Cluster de competitividade". Além delas, os demais players institucionais que constituem o tecido de apoio ao cluster são o Centro Tecnológico do Calçado de Portugal (CTCP) $)^{3}$ e a Associação Portuguesa dos Industriais de Calçado, Componentes, Artigos de Pele e seus Sucedâneos (APICCAPS) (Santos, 2018).

\footnotetext{
${ }^{3}$ O CTP auxilia o polo produtivo existente em São João da Madeira, Oliveira da Azeméis e Santa Maria da Feira. A produção realizada em Felgueiras é auxiliada pela Academia de Design e Formação. O outro polo está em Guimarães e conta com os serviços da Universidade do Minho.
} 
O CTCP é uma organização sem fins lucrativos criada em 1986, como resultado de uma parceria entre a APICCAPS e o governo português, com objetivo de fornecer apoio técnico e tecnológico às empresas da fileira do calçado e setores complementares, promoção da qualificação dos recursos humanos, promoção da melhoria da produção (produto e processo), preparação e divulgação das informações junto da indústria.

Criada em 1975, a APICCAPS é uma associação empresarial de âmbito nacional e as principais áreas de ação estão na internacionalização; na realização de estudos, projetos e consultoria; na assistência técnica; na disponibilização de informação; na formação; na contratação e negociação coletiva; no desenvolvimento de tecnologia e inovação, além da propriedade industrial e do desenvolvimento sustentável. Por meio dessas ações, a APICCAPS figura como a entidade responsável pela coordenação do cluster do calçado português e que, como afirma Santo (2015), na fase de reestruturação produtiva e de modernização da indústria calçadista, teve papel fundamental na coordenação do setor.

Dito isso, a existência de uma representação associativa comum consolida a identificação do cluster, uma vez que, para uma efetiva cooperação, é preciso que haja coordenação entre os atores, proporcionando o estreitamento e a densificação das relações entre os diferentes atores da cadeia produtiva, os quais resultam na intensificação das relações com a indústria de equipamentos, com a indústria dos acessórios de moda, com outros fornecedores de diversa natureza, com as empresas de distribuição de calçado e com as empresas e instituições ligadas ao universo do design e da moda, além das próprias entidades públicas portuguesas e europeias (APICCAPS, 2018, p. 11). A existência de um tecido institucional configura um ativo específico estratégico para o bom desempenho do cluster. A seguir, vamos aprofundar o entendimento sobre a entidade gestora da governança do cluster e o plano estratégico estabelecido sob a sua coordenação.

\section{A entidade responsável pela governança territorial do cluster}

Como já mencionado, a APICCAPS é a entidade responsável pela coordenação do cluster do calçado e que desenvolve um conjunto variado de ações, e, dentre as quais, destacamos a publicação de informações por meio de estudos e relatórios, como a Monografia 
Estatística, documento que apresenta detalhadamente a situação do setor de calçados em Portugal e no âmbito mundial.

Segundo informações obtidas no trabalho empírico, de um universo que varia de 300 a 400 associados, cerca de $90 \%$ são pequenas e médias empresas de cariz familiar. O estímulo a cooperação entre as empresas está imbuído no foco da produção, ou seja, o mercado externo. Com isso, a internacionalização torna-se o principal eixo de ação da entidade, como, por exemplo, a participação em feiras, importantes plataformas de atração de clientes, sejam feiras mundiais (grandes pontos de encontro da indústria do calçado), regionais (eventos direcionados para mercados com grande potencial para o calçado português) ou feiras de nicho (espaços especializados em determinados segmentos de mercado).

Soma-se ao incentivo à participação de feiras, a existência de projetos de $P \& D$, realizados sempre por meio de consórcios alargados com articulação setorial, articulação públicoprivado e articulação privado-privado, inclusive ações voltadas para a qualificação da mão de obra. Dentre as principais dificuldades do cluster, foi identificado, no trabalho empírico, a escassez de mão de obra qualificada, problema que não se limita a indústria do calçado, mas que tem sido indicado pelos empresários, segundo a entidade. Com isso, as ações para qualificar os recursos humanos têm sido uma aposta das empresas do cluster.

É importante destacar a articulação existente entre as empresas, como, por exemplo, quando uma empresa de calçado lidera um projeto com objetivo de alcançar um resultado específico (produto, máquina, processo, etc.), o resultado é compartilhado com todo o setor, o que evidencia um esforço de fortalecimento do território produtivo. Isso não significa que não haja competição entre os atores localizados, mas, que, em um contexto global acirrado, e fazendo uso da proximidade geográfica e organizacional, é possível que a articulação e o compartilhamento de recursos materiais e imateriais passem a ser recurso e ativo específico (Benko e Pecqueur, 2001), ou seja, uma vantagem competitiva (Porter, 1999).

A relação da entidade com o poder público é um aspecto a ser considerado. O poder público não participa efetivamente das discussões que envolvem diretamente a questão produtiva, ou seja, que envolvam o mercado, o que acarreta uma grande independência do setor 
privado no funcionamento do cluster. O apoio do poder público dos concelhos se dá essencialmente na resolução de problemas de infraestrutura, isto é, nas estradas, na iluminação, nos transportes, entre outros. Ao poder público federal está a responsabilidade de prover apoio regulatório e financeiro, como já mostrado anteriormente.

Ao buscar atender o "Regulamento de Reconhecimento dos Cluster de competitividade" e mostrando a importância em se elaborar estratégias para a melhoria da competitividade, a entidade apresentou, em 2013, o "Plano Estratégico do Cluster do Calçado 2014-2020". Segundo esse documento, o principal objetivo do cluster é, até o final da década, alcançar um crescimento qualitativo fortalecendo o processo de afirmação e reconhecimento internacional do calçado português, tornando-o uma referência a nível mundial. Para atingir esse objetivo, o plano propõe manter o cluster no caminho da sofisticação e da criatividade da oferta, não apenas dos seus produtos, mas também dos processos produtivos e dos seus modelos de negócio, o que garantiria a continuidade em segmentos de mercado exigentes e no qual a escolha do produto tem como métrica a qualidade, o conforto e o "bom gosto".

Ao retomar o Plano Estratégico anterior, implementado entre 2007-2013, a APICCAPS menciona as consequências da crise econômica que assolou a economia europeia no final da primeira década do século XXI, mesmo que o setor de calçados, como já afirmado anteriormente, não tenha sido fortemente afetado, como informa Santo (2015). A economia portuguesa foi uma das mais afetadas, culminando numa década de crescimento muito lento, acompanhada de uma preocupante crise das finanças públicas, atingindo o sistema financeiro e restringindo o financiamento ao setor produtivo. Essa situação fez que o Plano vigente reconhecesse a complexidade da economia globalizada e reforçasse a necessidade de manter uma base nacional produtiva competitiva em uma economia globalizada e que não cedesse aos apelos protecionistas. A flexibilidade, a rapidez de resposta e a exigência cada vez maior da qualidade do produto têm se tornado condicionante da concorrência, assim como a adoção aos padrões de sustentabilidade ambiental e de responsabilidade social.

Com relação às capacidades do cluster do calçado, o plano assinala a base industrial diversificada e a capacitada para o cenário competitivo internacional. Com uma mão de obra portadora de know-how ("saber fazer"), projeta-se como um diferencial na garantia da qualidade e especificidade do produto português mundialmente reconhecido. Outra 
característica a ser destacada é o patrimônio de cumplicidade (cooperação e confiança) entre os empresários e as instituições de apoio, essenciais para a atuação do cluster.

Como visto, a indústria portuguesa do calçado figura como uma das principais frentes produtivas do país, situando Portugal no rol dos produtores competitivos. Como já mencionado, o diferencial do calçado português não está no baixo custo de sua produção e na sua produção em larga escala (casos da indústria chinesa e vietnamita), mas, sim, na qualidade, sofisticação e criatividade. A indústria portuguesa definiu sua frente de atuação no mercado internacional colocando-se em um nicho de atuação seleto, no qual a Itália é líder.

É interessante observar que, no Plano estratégico, contribuir para a coesão social é uma dimensão ou objetivo do cluster. A discussão da coesão social na Europa é um dos pilares do pacto europeu que sustenta a União e, ao adotar a coesão, o cluster se apresenta perante a sociedade portuguesa e europeia obtendo visibilidade e reconhecimento político e social.

O Plano cita que a "base produtiva [indústria do calçado] tem que pautar-se por elevados padrões de sustentabilidade e responsabilidade social, contribuindo para os objetivos de desenvolvimento da sociedade portuguesa". Ainda segundo o plano, o cluster está "bem consciente do contributo que tem dado, e pretende continuar a dar, para a coesão social nas zonas geográficas em que predominantemente está implantado. Assim como está consciente das suas obrigações em matéria de sustentabilidade ambiental" (APPICAPS, 2013, p.41).

Por fim, para atingir a esses complexos objetivos, o cluster não deve manter unicamente a fórmula de sucesso, mas é preciso uma estratégia de desenvolvimento, no qual o conhecimento e a inovação são os pilares. Só assim, valorizando estratégias de conhecimento e inovação, que o cluster do calçado português atingirá níveis superiores de sofisticação em relação a seus concorrentes, além de manter "uma base produtiva nacional e assumir as suas responsabilidades perante a sociedade, preservando a sua competitividade" (APPICAPS, 2013, p.41).

No conjunto de publicações disponibilizadas pela APPICAPS não há um levantamento ou diagnóstico sobre o desenvolvimento do Plano estratégico 2014-2020, mas algumas informações sobre outras iniciativas têm sido divulgadas. Em 2018, a APICCAPS e o CTCP 
criaram o "Roteiro do Cluster do Calçado para a Economia Digital - FOOTURE 4.0" ${ }^{4}$, iniciativa que envolve mais de 70 entidades, entre empresas, startups, universidades, centros de inteligência e entidades do sistema científico e tecnológico, com o objetivo de explorar as oportunidades criadas pela Indústria 4.0. Para isso, foram definidas quatro prioridades estratégicas: (1) criar formas de interação com o cliente num contexto digital e em rede (ecommerce); (2) melhorar a flexibilidade, o tempo de resposta ao cliente, a inteligência de negócios e sustentabilidade ("Fabrico Inteligente"); (3) qualificar o setor para a Indústria 4.0, tornando-o mais dinâmico, inovador e capaz de criar novos negócios; (4) melhorar a inteligência e a imagem do setor.

Em 2019, a APICCAPS $^{5}$ divulgou que 278 empresas estão envolvidas nos projetos apresentados para o FOOTURE 4.0 e que destinam os recursos para a melhoria da produção (compra de novos equipamentos), da comercialização (desenvolvimento de coleções, registro de marcas e ações de promoção e marketing), além da internacionalização (promoção comercial externa).

Ao analisar os esforços de cinco empresas de calçados na transição para a indústria 4.0, Santos (2018) indica o FOOTURE 4.0 como uma das principais ações do cluster para a modernização e o desenvolvimento do setor em um ambiente cada vez mais competitivo. Para ele, ao analisar as ações das empresas e da APPICAPS, a transição para a indústria 4.0 é prioridade no cluster e tem resultado em mudanças na organização em termos produtivos, comerciais e na definição das suas estratégias para o futuro. Nesse processo, o e-commerce tem assumido grande importância nessa transição, uma vez que remodela a forma de comercialização (marketing digital e valorização das marcas), bem como a forma que a empresa se relaciona com o cliente (utilização de ferramentas como as redes sociais, serviços de anúncios digitais, blogs e campanhas de marketing direcionadas via correio eletrônico).

Ao elaborar um conjunto de cinco recomendações para o setor calçadista português, Santos (2018) afirma a necessidade do Estado, em parceria com os demais atores do cluster, melhorar a sua atuação, tendo, como foco, a facilitação do processo burocrático e o apoio à

\footnotetext{
${ }^{4}$ APPICAPS. FOOTure 4.0 em marcha. Disponível em: https://www.apiccaps.pt/news/footure-40-emmarcha/3045.html. 2018. Acessado em 05 abril 2020.

${ }^{5}$ APICCAPS. Indústria 4.0: Calçado na frente. Disponível em: https://www.apiccaps.pt/news/industria-40calcado-na-frente/4184.html. 2019. Acessado em 05 abril 2020.
} 
formação de mão de obra qualificada em engenharia, informática e outros, que, devido à alta procura podem resultar em problemas para as empresas e para a economia nacional.

Vivenciando uma verdadeira "época de ouro", consolidando-se como uma das principais atividades produtivas da economia nacional e se destacando no conjunto europeu como um aglomerado produtivo de sucesso, o setor calçadista se depara com um novo desafio, a indústria 4.0. Essa novidade industrial inaugura um novo período na história do setor, o qual abarca questões da qualidade, da inovação, da tecnologia e da criatividade junto a uma característica territorial, a produção artesanal.

Por fim, em relação às características da governança territorial do cluster, temos a existência e o envolvimento de diferentes atores, como a associação empresarial, os centros de pesquisa e inovação, os órgãos públicos, as empresas e as universidades compondo o bloco socioterritorial (consistência da rede). A articulação entre os atores, ou seja, o movimento de concertação social, fica sob a responsabilidade da APICCAPS, entidade que lidera a rede de poder socioterritorial, haja vista o seu papel de principal entidade representativa do setor no país. As ações diretamente voltadas ao cluster e que poderíamos identificar como pactos socioterritoriais, estão voltadas para a modernização do parque produtivo atendendo as exigências da indústria 4.0, ao apoio à internacionalização, a qualificação da mão de obra e na captação de recursos públicos, em especial, aqueles vindos da União Europeia. Sobre o tipo de governança manifestada no cluster do calçado português, afirmamos que é de caráter privado-coletivo, uma vez que o ator chave, a APICCAPS, é uma organização formal que agrupa operadores privados e impulsiona a coordenação de recursos e estratégias.

\section{Considerações finais}

Este artigo procurou analisar a importância da governança territorial em aglomerados produtivos. Por meio de um exercício de revisão bibliográfica e de análise de documentos oficiais, buscamos entender como a governança territorial, com base em contribuições que a abordam sob o prisma urbano e produtivo, contribui para o desempenho do cluster do calçado português. 
Sobre a governança territorial, entendemo-la como um novo modo de cooperação e de coordenação dos territórios para o desenvolvimento e que, ao considerar o conjunto de mudanças geradas pelo processo de globalização, surge como um novo fator de localização, específico e incomensurável. Esse novo fator de localização, ao promover a articulação entre atores sociais distintos em um território com dimensão multiescalar, reforça o entendimento de que as novas estratégias de desenvolvimento possuem caráter mais difuso e são sustentadas por fatores não apenas econômicos, mas também por fatores sociais, culturais e territoriais, os quais podem ser observados em diferentes recortes geográficos e setoriais.

A literatura identifica os clusters como exemplos de modalidades de governança. Na Europa, Portugal figura no rol dos países com aglomerações produtivas de diferentes níveis tecnológicos, desde atividades mais tradicionais, como o têxtil e o calçado, até as mais avançadas, como o setor de saúde e de telecomunicações. Os clusters são considerados instrumentos estratégicos no desenvolvimento produtivo português, o que é atestado quando observamos os diferentes estudos governamentais sobre o tema. É importante reconhecer que a política de apoio aos clusters se configura como uma das mais relevantes ações públicas de apoio à atividade industrial em Portugal, o qual é fundamental para a economia nacional, pois resulta em incrementos econômicos e reduz a dependência do país do turismo, atividade econômica que tem aumentado a participação no emprego e na renda portuguesa.

A mais recente iniciativa de Portugal para o apoio aos aglomerados produtivos, 0 "Regulamento de Reconhecimento dos Clusters de Competitividade", inseriu a governança dentre os fatores que podem resultar no sucesso ou no insucesso das estratégias e enfatiza a necessária participação de todos os atores envolvidos no cluster, sendo que, o seu funcionamento deve estar pautado em regras que garantam a continuidade, bem como a legitimidade do modelo em situações de conflito. O insucesso da governança ou a ausência de atores pode resultar na desmobilização dos atores, prejudicando o cluster. O Regulamento é um exemplo do esforço do poder público português em potencializar os clusters como estratégia de desenvolvimento regional, dispondo de instituições específicas para a sua promoção, bem como de recursos oriundos da União Europeia. 
O cluster do calçado português é um exemplo interessante desse esforço, pois se situa como um cluster estratégico na geração de renda e de emprego, contribuindo para o desenvolvimento da região norte de Portugal - região que está na classificação europeia de regiões de baixa densidade/baixo desenvolvimento. Conhecida como "a indústria mais sexy da Europa", a indústria calçadista portuguesa, representada pelo cluster, consolidou-se como símbolo nacional, superando os problemas que outrora vivenciou. Seu sucesso nos permitiu observar a importância dos recursos e dos ativos territorializados, do "saber fazer", da aglomeração e da essencialidade da cooperação entre os atores e da sua necessária coordenação. Trata-se de um interessante caso para estudos sobre aglomerações produtivas e que pôde, nesse artigo, contribuir com a discussão proposta, entender a importância da governança territorial em aglomerados produtivos, como os clusters.

O sucesso do cluster, além dos apoios governamentais, deve-se principalmente a articulação entre as empresas envolvidas na cadeia produtiva e a participação de instituições de apoio, como as entidades setoriais e as universidades portuguesas. Em relação às empresas, diante de uma situação de intensificação da competitividade da indústria calçadista asiática, as empresas portuguesas do setor iniciaram um processo de modernização da produção, no qual a articulação entre as empresas foi essencial.

Nesse processo de modernização e de articulação entre as empresas, a existência de entidades setoriais de auxílio aos empresários foi importante, como a APICCAPS. Essa associação empresarial conseguiu construir, junto aos empresários do cluster, um ambiente institucional pautado na coordenação de diferentes atores e que apresentava algum envolvimento com o setor calçadista para o bom desenvolvimento das atividades do cluster, independente dos momentos de crise ou de fartura. Ao fornecer o respaldo técnico, político e contribuindo com a resolução de problemas internos, a APICCAPS é a representante da governança do cluster, uma governança territorial composta por representantes de empresas e do poder público, mas que caracterizamos como uma governança privadacoletiva.

A dinâmica territorial, tanto a questão produtiva como a articulação institucional do cluster, denota a importância estratégica da governança para o bom desempenho do aglomerado, além de oferecer, com base no estudo de caso, um excelente exemplo para a discussão 
sobre a dinâmica em aglomerados produtivos e a relevância dos novos fatores de produção (conhecimento, inovação, articulação entre atores, apoio institucional, entre outros).

Com isso, o cluster apresenta uma rede consistente de atores. As atividades que podem ser impulsionadas pelo cluster estão voltadas ao complexo industrial coureiro-calçadista que possui forte imbricação territorial e que se mostrou capaz de se adaptar frente aos processos de reestruturação da produção. Com relação à consistência das estratégias, observa-se o atendimento ao "Regulamento de Reconhecimento dos Cluster de competitividade" a partir da elaboração e do cumprimento do "Plano Estratégico" e da adoção de iniciativas de modernização do parque produtivo com base na indústria 4.0. Além do mais, a entidade gestora desenvolve atividades de acompanhamento sobre o funcionamento do cluster publicando estudos e relatórios de análise sobre o setor.

Em conclusão, pode-se dizer que a governança territorial do cluster do calçado é um importante recurso específico do território local. A governança equivale a um instrumento de poder em que os atores locais expõem suas necessidades e problemas, discutem possíveis soluções, mobilizam capital e alcançam soluções para muitos problemas em comum no setor do calçado. É desse ambiente complexo de interesses que se deve buscar certo equilíbrio para o bom desempenho do setor, gerando vantagens competitivas para as empresas do cluster.

Por fim, as mudanças na escala do planejamento e da gestão dos territórios, versando a realocação de responsabilidades e a atuação de diferentes atores territoriais, não são apenas novidades de um período marcado pela globalização, mas correspondem a uma necessidade na construção de um desenvolvimento socioeconômico que passe pelo reconhecimento da importância das dinâmicas territoriais multiescalares. Dito isso, a governança representa um instrumento de viabilização desse processo de reconhecimento, reforçando um recurso específico e, consequentemente, intransferível e incomensurável. Não se trata apenas de uma aposta teórica, mas, também, uma aposta de cunho político. 


\section{Agradecimentos}

Agradecemos à Fundação de Amparo à Pesquisa do Estado de São Paulo (FAPESP) pelo financiamento da pesquisa (Processo 18/19564-5) intitulada “Governança, atores e desenvolvimento: uma análise sobre as mudanças na escala de planejamento, realocação de responsabilidades e atuação dos atores territoriais".

\section{Referências bibliográficas}

Alcântara, R. (2017). Governança como modelo de gestão dos territórios: um olhar sobre o douro vinhateiro. Revista Finisterra - Centro de Estudos Geograficos, LII, 106, pp. 129 -148.

APICCAPS. Brochura Institucional. Disponível em: https://www.apiccaps.pt/. Vários Acessos.

APICCAPS. Monografia Estatística - Calçado, Componentes e Artigos de Pele. (2017). Disponível em: https://www.apiccaps.pt/publications/monografia-estatistica/112.html. Acessado em: 15 dez 2018.

APICCAPS. Plano Estratégico do Cluster do Calçado 2014-2020. Disponível em: https://www.apiccaps.pt/publications/plano-estrategico/116.html. Acessado em: 20 dez 2018.

Becattini, G. (1994). O distrito marshalliano. In.: BENKO, G.; LIPIETZ, A (org.). As Regiões Ganhadoras. Distritos e Redes: Os novos paradigmas da Geografia Econômica. Oeiras-Portugal: Celta Editora.

Benko, G.; Pecqueur, B. (2001). Os recursos de territórios e os territórios de recursos. Geosul - Revista do Departamento de Geociências, Florianópolis, v. 16, n. 32, p. 31-50, jul. /dez.

Carmo, F. (2014). Planos Regionais de Ordenamento do Território e governança territorial: do discurso às evidências da prática. Revista de Geografia e Ordenamento do Território, 5, 41 -65.

Carmo, J. de A. do. (2014). As articulações entre comércio e distribuição na dinâmica da produção em aglomerado produtivo calçadista de Portugal. GEOUSP - Espaço e Tempo (Online), São Paulo, v. 18, n. 1, p. 83-96.

Chamusca, P. (2013). Novos desafios e objetos de governação territorial: discutindo a reorganização do Estado e a conceptualização da governança como modelo de gestão dos territórios. Revista de Geografia de Ordenamento do Território. Dez.

ChorincaS, J. (2009). Estratégias de Eficiência Colectiva (EEC) - Notas de apoio a participação do Observatório do QREN na Comissão de Avaliação das EEC. Coleção e+cadernos do Observatório do QREN.

COMISSÃO EUROPEIA. (2001). Governança Europeia. Um Livro Branco. Bruxelas: Comissão das Comunidades Europeias.

Courlet, C. (2013.). Os sistemas produtivos localizados: da definição ao modelo. Revista Internacional Interdisciplinar - Interthesis. UFSC, v. 10, n. 02.

Fernandes, J. A. R.; Chamusca, P. (2009). Governância, planeamento e estratégias de desenvolvimento territorial: reflexões a propósito da teoria e da prática. Inforgeo, 24, 27-43.

Ferrão, J. (2010). Governança e Ordenamento do Território. Reflexões para uma governança territorial eficiente, justa e democrática. Revista Prospectiva e Planeamento, Lisboa, v. 17, p. 129-139.

Ferreira, C. A. A.; Natário, M. M. S.; Braga, A. M. M. (2008). Análise e avaliação ao funcionamento dos clusters em Portugal reconhecidos pelo QREN. Economía, Sociedad y Territorio, vol. xviii, núm. 57, p. 585-620.

Fuini, L. L. (2015). Território e competitividade: relações, teorias e aplicações. 1. ed. Jundiaí/SP: Paco Editorial. 
Lastres, H. M. M.; Cassiolato, J. E. (2003). Glossário de Arranjos e Sistemas produtivos e Inovativos Locais. REDESIST. IE/UFRJ, SEBRAE. Novembro.

Leloup, F.; Moyart, L.; Pecqueur, B. (2005). La gouvernance territoriale comme nouveau mode de coordination territoriale ? Revue Géographie, Économie, Societé, v.7, p.321-332.

Loureiro,S. M. C.; Santo, R. do E.; Sarmento, E. M. (2017). Analysis of the footwear cluster in Portugal: competitiveness and internationalization. R-LEGO - Revista Lusófona de Economia e Gestão das Organizações, N.․․ 5 .

Moreira, R. A. (2014). Política de clusters - o conceito de cluster enquanto catalisador do desenvolvimento territorial - as EEC do QREN. Dissertação de Mestrado. Universidade de Lisboa.

Pires, E. L. S. et al. (2017). A Governança Territorial Revisitada: dispositivos institucionais, noções intermediárias e níveis de regulação. Geographia, Niterói, vol. 19, n. 41.

Pires, E. L. S. et al. (2011). Governança Territorial: Conceitos, Fatos e Modalidades. Rio Claro: Editora da PósGraduação em Geografia/ IGCE/ UNESP.

Porter, M. (1999). Competição: Estratégias Competitivas Essenciais. Rio de Janeiro, Ed. Elsevier/ Campus.

PORTUGAL. Despacho n. 2909/2015. Diário da República. 2. a série - N.o 57 - 23 de março de 2015

Santo, R. do E. (2015). Análise ao cluster do calçado em Portugal: comparação de players e perspetivas futuras para o sector. Dissertação (Mestrado em Gestão). ISCTE, Instituto Universitário de Lisboa.

Santos, F. M. F. V. B. (2018). O setor do calçado em Portugal e a sua transformação à luz da indústria 4.0: um estudo de caso múltiplo. Dissertação de Mestrado. Universidade de Lisboa. Out.

Silva, M. (2019). A arte de fazer sapatos: modos de fazer e de apresentar na indústria de calçado portuguesa. Cadernos de Arte e Antropologia. Vol. 8, n. 1.

Storper, M; Harrison, B. (1994). Flexibilidade, Hierarquia e Desenvolvimento Regional. In: G. Benko, A. Lipietz. As Regiões Ganhadoras - Distritos e Redes: Os Novos Paradigmas da Geografia Económica. Oeiras: Celta Editora.

Vale, M.. (2009). Conhecimento, Inovação e Território. Finisterra, XLIV, 88.

Vale, M.; Caldeira, J. (2006). Proximity and Knowledge Governance in Localised Production Systems: the Footwear Industry in the North Region of Portugal. European Planning 